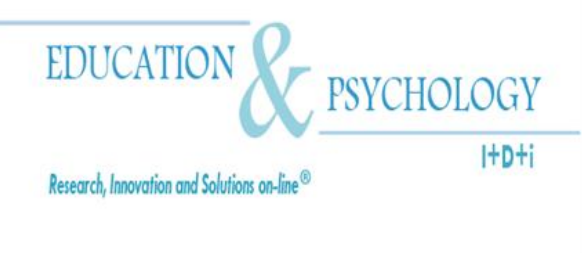

\title{
Examining the Psychometric Properties of the Achievement Goals Questionnaire among Nigerian Preservice Mathematics and Science Teachers
}

\section{Adeneye O. A. Awofala ${ }^{1}$, Abayomi A. Arigbabu ${ }^{2}$, Alfred O. Fatade $^{2}$, Awoyemi A. Awofala ${ }^{3}$}

${ }^{1}$ Department of Science and Technology Education, University of Lagos, Lagos

${ }^{2}$ Department of Mathematics, Tai Solarin University of Education, Ijagun

${ }^{3}$ Department of Biological Sciences, Tai Solarin University of Education, Ijagun

\section{Nigeria}




\begin{abstract}
Introduction. The stability of the achievement goal orientation across different contexts has been a source of further research since the new millennium. Through theoretically-driven and empirically-based analyses, this study investigated the psychometric properties of the Elliot and McGregor $2 \times 2$ framework for achievement goal questionnaire within a communal context.
\end{abstract}

Method. Based on classical test theory, the present study attempted to explore the stability of the $2 \times 2$ framework for Achievement Goal Questionnaire (AGQ) using exploratory factor analysis involving the principal components extraction with orthogonal and oblique rotations.

Results. Results support the factor structure of the $2 \times 2$ achievement goal framework in the collectivist culture context.

Discussion. The present study provides evidence that suggests that achievement goal construct as measured by AGQ, appears to be culturally and contextually invariant thus reinforcing the four-factor model namely mastery-approach, performance-approach, masteryavoidance, and performance-avoidance in domain specific context. Future research should focus on determining the psychometric properties of the $2 \times 2$ achievement goals in Mathematics Education Questionnaire and Science Education Questionnaire using both the classical test theory and modern item response theory to refute or generalise existing results.

Keywords: achievement goals questionnaire, preservice teachers, psychometric properties, mathematics, science, Nigerian 


\section{Propiedades psicométricas del cuestionario de metas de logro en una muestra de profesores nigerianos de matemáticas y ciencias naturales en su etapa de formación inicial \\ Resumen}

Introducción. La estabilidad de la orientación de meta de logro, a través de diferentes contextos ha sido una fuente de nuevas investigaciones, en el nuevo milenio. A través de análisis teóricamente impulsados y con base empírica, este estudio investigó las propiedades psicométricas de la Elliot y McGregor $2 \times 2$ marco para el cuestionario metas de logro, en un contexto comunitario.

Método. De acuerdo con la teoría clásica de los tests, el presente estudio trató de explorar la estabilidad del marco $2 \times 2$ para el cuestionario metas de logro (AGQ) utilizando exploratorio factor de análisis que implica la extracción de componentes principales con rotaciones ortogonales y oblicuas.

Resultados. Los resultados apoyan la estructura factorial de $2 \times 2$ marco objetivo el logro en el contexto de la cultura colectivista.

Discusión. El presente estudio proporciona evidencia que sugiere que la meta de logro constructo medido por AGQ, parece ser cultural y contextualmente invariable tanto reforzando ción del modelo de cuatro factores a saber, el dominio - enfoque, el rendimiento enfoque, el dominio de evitación y rendimiento de evitación en contexto específico del dominio. La investigación futura debe centrarse en determinar las propiedades psicométricas de los $2 \times 2$ metas de logro en Cuestionario Educación Matemática y el Cuestionario de Educación en Ciencias, con la teoría clásica de los tests y el tema moderna teoría de respuesta para refutar o generalizar los resultados existentes.

Palabras clave: Logro de los Objetivos del cuestionario, educadores en formación, propiedades psicométricas, matemáticas, ciencias, Nigeria. 


\section{Introduction}

Achievement goal theory has emerged a formidable area of academic and experimental inquisition in educational psychology (Muís, Winne, \& Edwards, 2009) with attendant impact on motivational constructs in organizational research reflecting individual differences in work-related behaviours and task performance outcomes (McKinney, 2003). Achievement goal orientation (AGO) is one of such constructs that forms a set of behavioural intentions that determine how students approach and engage in learning activities (Meece, Blumenfeld \& Hoyle, 1988) and reflects internal motivational processes that affect an individual's task choice, self-set goals, and effort mechanisms in learning and performance contexts (Fisher \& Ford, 1998; Phillips \& Gully, 1997; VandeWalle, 1997; Button, Mathieu, \& Zajac, 1996). AGO is concerned with why a person approaches a task in a certain manner (Owens, 2004) and has been associated with task difficulty preference and level of interest one has in a topic (Harackiewicz, Barron, Tauer, Carter, \& Elliot, 2000; Harackiewicz \& Elliot, 1998; Harackiewicz, Barron, Carter, Lehto, \& Elliot, 1997).

Achievement goal orientation is defined as the purposes for behaviour that are perceived or pursued in a competence-relevant setting (Midgley, Kaplan, \& Middleton, 2001). A variety of studies has linked goal orientation to students' cognitive and behavioural reactions (Ames \& Archer, 1988; Ames, 1992), individual differences in self-regulatory behaviours (Alao \& Guthrie, 1999; Somuncuoglu \& Yildirim, 1999; VandeWalle, Brown, Cron \& Slocum, 1999; Ford, Smith, Weissbein, Gully, \& Salas, 1998), feedback-seeking behaviour (VandeWalle \& Cummings, 1997), test anxiety (Elliot \& McGregor, 1999; Middleton \& Midgley, 1997), low self-efficacy (Saalvik, 1997), intrinsic motivation (Elliot \& Church, 1997; Elliot \& Harackiewicz, 1996), intelligence (Was, 2006), and motivation to learn (Colquitt \& Simmering, 1998; Ford, Smith, Weissbein, Gully, \& Salas, 1998).

More so, goal orientation has been linked to individual differences in academic performance (Valle, Cabanach, Núñez, González-Pienda, Rodríguez, \& Piñero, 2003; VandeWalle, Cron, \& Slocum, 2001; Chen, Gully, Whiteman, \& Kilcullen, 2000; Beaubien \& Payne, 1999; Phillips \& Gully, 1997), training performance (Brown, 2001; Kozlowski, Gully, Brown, Salas, Smith, \& Nason, 2001; Brett \& VandeWalle, 1999), task performance (Mangos \& Steele-Johnson, 2001; Steele-Johnson, Beauregard, Hoover, \& Schmidt, 2000), and sales performance (VandeWalle et al., 1999). Early conceptualisation of AGO revealed a two- 
factor model: learning goal orientation (sometimes referred to as mastery goal orientation) and performance goal orientation (Dweck, 1986) alternatively termed task vs. ego or learning vs. ability (Seo, 2000; Ames \& Archer, 1988; Nicholls, 1975) although nuanced differences exist between the terminologies (Pintrich \& Schunk, 2002; Järvelä, 1996; Ames, 1992). In short, learning goals are also known as mastery goals (Ames \& Archer, 1988) or taskinvolved goals (Nicholls, Patashnick, \& Nolen, 1985). Similarly, performance goals are also considered ego-involved goals (Nicholls et al., 1985) or ability goals (Ames \& Archer, 1988; Dweck \& Leggett, 1988; Dweck, 1986). While literature is replete with debates over the stability of AGO; that is, whether goal orientation should be operationalised as a state or as a trait (Cellar, Stuhlmacher, Young, Fisher, Adair, Haynes, \& Twichell, 2011; Payne, Youngcourt \& Beaubien, 2007; DeShon \& Gillespie, 2005; VandeWalle, Cron, \& Slocum, 2001; Button, Mathieu, \& Zajac, 1996), converging evidence suggests that trait and state goal orientation interact, so both operationalisations should be considered simultaneously (DeGeest \& Brown, 2011).

Relying on the work of Dweck (1986), VandeWalle (1997) proposed that goal orientation is better conceptualized as a three-factor model, further dividing performance goal orientation into the dimensions of avoidant performance goal orientation (APGO) and prove performance goal orientation (PPGO). APGO is rooted in a fear of failure and negative judgment from others while in PPGO a learner strives to demonstrate aptitude to prove competence and seek favourable judgments (Elliot \& Church, 1997). Research (Elliot \& McGregor, 2001; Elliot \& Church, 1997; Elliot \& Harackiewicz, 1996) has suggested the examination of four-factor model of AGO in a $2 \times 2$ achievement goal framework based on goal definition (mastery vs. performance) and valence (approach vs. avoidance), namely mastery approach goals (MAPGs), mastery avoidance goals (MAVGs), performance approach goals (PAPGs), and performance avoidance goals (PAVGs).

In this conceptualisation, individuals define goals in either intrapersonal terms aiming at task mastery, or in normative sense, focusing on task performance. In terms of valence, individuals exhibit either a positive (approaching success) or negative (avoiding failure) approach to mastery and performance orientations (Elliot \& McGregor, 2001).While MAPGs emphasize task mastery and deep understanding, MAVGs focus on avoiding misunderstanding. On the other hand, PAPGs emphasize showing abilities to others and getting the highest grades, whereas PAVGs focus on avoiding looking dumb and being inferior (Elliot \& Reis, 
2003; Pintrich \& Schunk, 2002; Elliot \& McGregor, 2001; Elliot \& Church, 1997). Elliot and McGregor (2001) have examined the feasibility of the four-goal model and in factor analyses have found empirical support for the differentiation of the four goals and Akin (2012) found that mastery-approach/avoidance goal orientations have increased while performanceapproach/avoidance goal orientations have decreased with age.

In line with many other psychological constructs, various scales have been developed to measure AGO in its unidimensional form (Ames \& Archer, 1987; Bandura \& Dweck, 1985), dichotomous form (Button, Mathieu, \& Zajac, 1996; Heyman \& Dweck, 1992; Nicholls, Cobb, Wood, Yackel, \& Patashnick, 1990), trichotomous form (VandeWalle, 1997; Elliot \& Church, 1997; Elliot \& Harackiewicz, 1996), and presently along the $2 \times 2$ framework of four dimensions (Akin, 2012; Was, 2006; Elliot \& McGregor, 2001).

In its four-dimensional form, the instrument developed by Elliot and McGregor (2001) has been most researched and the validity and utility of this $2 \times 2$ framework of achievement goals have been demonstrated for middle school and college students across Western and Eastern cultures (Barzegar, 2012; Dinc, 2010; Bong, 2009; Adie, Duda, \& Ntoumanis, 2008; Coutinho \& Neuman, 2008; Nien \& Duda, 2008; Sideridis, 2008; Njouku, 2007) with the premonition that the former cultures tend to be individualistic while the latter cultures gravitate towards collectivism (Fiske, 2002), a distinction that could breed different cultural-based meanings of achievement goals (Alkharusi, 2010). The factor structure of the Achievement Goal Questionnaire (Elliot \& McGregor, 2001) has been examined in a general academic context with a sample of 2111 freshman undergraduate students who completed the AGQ along with other various instruments (Finney, Pieper, \& Barron, 2004).

Results supported the four-factor structure originally hypothesised (Elliot \& McGregor, 2001) and correlations between each of the four dimensions were low, with Cronbach alpha reliability coefficients greater than .70 except for the performance avoidance subscale (.54). Psychometric properties of the $2 \times 2$ framework of achievement goal orientations has been investigated with specific samples (Elliot \& McGregor, 2001), between groups to assess factorial invariance (Midgley et al., 1998), across general or domain-specific contexts (Finney, et al., 2004; Jagacinski \& Duda, 2001) with recent attention being given to the exploration of the stability of goal orientations across contexts (Muis \& Edwards, 2009; Fryer \& Elliot, 2007; Senko \& Harackiewicz, 2005; Winne, Muis, \& Jamieson-Noel, 2005). 
Recently, Muis and Winne (2012) investigated factorial invariance across four different task contexts after receiving feedback about those tasks, and also examined construct- and discriminant-related evidence of validity and reliability of the items on the AGQ with a sample of 99 university undergraduate students enrolled in an introductory educational psychology course. Results revealed that the hypothesized four-factor structure was replicated, construct- and discriminant-related evidences of validity were supported, and both internal consistency and test-retest reliability estimates were satisfactory. Moreover, invariance held at all levels across the various contexts.

However, the extent to which the $2 \times 2$ framework of achievement goal orientations is applicable to the Nigerian culture is yet to be determined and relying on Urdan (2004) argument, there might be cultural differences in the pursuit and consequences of achievement goals that may not have been sufficiently researched, and as such there have been calls for more cultural research in this area (Muis, Winne, \& Edwards, 2009; Wang, Biddle \& Elliot, 2007; Chan \& Lai, 2007) thus setting the stage for its investigation in the present study. For instance, Tao and Hong (2000) found that in the Chinese culture, mastery goals are positively related to performance goals, whereas in the American culture, mastery goals and performance goals tend to be correlated negatively with each other. As contended by Tao and Hong (2000), academic achievement in the Chinese culture tends to be a social-oriented endeavour whereas in the American culture it is an individual endeavour. In response to these calls, this study sought to test the validity of the $2 \times 2$ framework of achievement goal orientations within the context of African students in Nigeria, often known to cohabit in a communal society (Awofala \& Awolola, 2011) like those in Arab world (Aldhafri, Kazem, Alzubiadi, Yousif, Al-Bahrani, \& Alkharusi, 2009).

Besides being the first study in Nigeria, this attempt would expand the applicability of the $2 \times 2$ framework of achievement goal orientations in Africa and understanding students' achievement goals in Nigeria could serve as way of helping educators develop appropriate teaching and learning practices for preservice science and mathematics teachers. Although factor analytic procedures were adopted in the present study, previous results of factor analytic procedures from studies conducted on college level students showed that the performance-approach and performance-avoidance goals are independent orientations (Elliot \& Church, 1997), whereas studies conducted on middle school students tended to reveal some 
degree of overlap between these two types of goals (Middleton \& Midgley, 1997). The present study would seek to shed light on this relationship for preservice mathematics and science teachers in a first generation university in South West geo-political zone of Nigeria using the $2 \times 2$ framework of achievement goal orientations generally considered to be the most prevalent goal framework in achievement settings (Canpolat, 2012; Muis \& Winne, 2012; Diseth, 2011; Roussel, Elliot, \& Feltman, 2011; Smith, Smoll, \& Cumming, 2009; Muis, Winne, \& Edwards, 2009; Elliot \& Murayama, 2008; Kim, 2008; Roebken, 2007; Elliot \& McGregor, 2001; Elliot \& Thrash, 2001).

More so, that the Elliot and McGregor AGQ was developed in the last 12 years precisely in 2001 in more advanced and technologically developed culture, hence the present study sought to examine whether the psychometric characteristics of AGQ would be preserved in another relatively less advanced and less developed culture, with the premonition that advances in knowledge in the recent past might have triggered off some subtle differences. Thus, the reliability and validity of the AGQ would be established vis-as-viz the dimensions of the questionnaire. We are not unaware of the fact that the traditional psychometric properties of the AGQ have been assessed in terms of classical test theory (Elliott \& McGregor, 2001) with the reported internal consistencies (alphas) of the instrument criticised for being too high with items soliciting the same response because of poor wording and few items per latent construct (Adesope, Carmen, \& Nesbit, 2008). More so, some researchers have questioned the psychometric properties associated with goal orientation measures (Vandewalle, 1997), and few studies have investigated the constructs of AGQ using item response theory (IRT) (Adesope, Carmen, \& Nesbit, 2008) in which Muis, Winne and Edwards (2009) focused on the one parameter Rasch model approach of IRT to investigate the psychometric properties of AGQ.

Muis et al (2009) found that Rasch analyses revealed good estimates of item reliability but respondent ability estimates varied from poor to good. While Muis et al (2009) study contributes to our understanding of the problems associated with using AGQ for measuring students' academic goals, their use of Rasch analysis approach somewhat undermines the result because Rasch analysis only examines the difficulty of items but does not account for discrimination among items in a scale. This is a fruitful area of further research. Adesope, Carmen, and Nesbit (2008) proposed the use of two-parameter partial credit model (2PPC) that takes the discrimination parameter into consideration and examined how items of AGQ dis- 
criminate across different levels of goal-setting abilities. Their findings provided support for the four factor model of achievement goal orientation but also advocated better item scale design for measuring students' academic goals since the item response theory analyses revealed a hugely limited effectiveness of many items of this instrument in measuring achievement goal.

Stevenson (2011) conducted a study involving a random-effects model of the HunterSchmidt method of meta-analysis on the relationship between an antecedent or consequence variable and at least one of the goals defined by Elliot's (1999) 2 x 2 model of achievement motivation for 77 studies published in English between 1999 and 2010. Effect sizes for common antecedents $(n=7)$ and consequences $(n=3)$ in the physical activity and education domain were examined. Results indicated low to moderate sized effect sizes for most antecedents in physical activity and education, whereas large effect sizes were typically found for most significant consequences. Based on the results of the study, Stevenson (2011) maintained that intervention for positive goal adoption (mastery-, performance-approach) should focus on providing a mastery climate and increases in perceived competence, while avoiding a focus on fear of failure.

\section{Objective}

This meta-analysis (Steveson, 2011) happened to be the first to be conducted since the development of the $2 \times 2$ model of achievement goal and presently in Nigeria no published work has been done on examining the traditional psychometric properties of the AGQ using the classical test theory, let alone the more advanced item response theory (IRT). This study therefore, examined the psychometric properties of the AGQ within the context of the classical test theory.

\section{Methods}

\section{Participants}

The participants consisted of 680 preservice teachers in a first generation conventional university in southwest Nigeria: 400 (58.8\%) studied science [208 (52\%) men and 192 (48\%) women] and $280(41.2 \%)$ studied mathematics [144 (51.4\%) men and 136 (48.6\%) women] Altogether their ages ranged between 16 and 30 years $(\mathrm{M}=24.3, \mathrm{SD}=2.4)$. The participants 
could also be categorised into $24 \%$ in the final year, $28 \%$ in the third year, $22 \%$ in the second year, and $26 \%$ in the first year of a four-year degree programme. The science cohort comprised biology, chemistry, and physics preservice teachers. The sample size of 680 was considered very good and appropriate since 300 cases are considered good as a general rule of thumb for factor analysis or principal components analysis (Comrey \& Lee 1992; Tabachnick \& Fidell, 2001).

\section{Instrumentation}

The English version of the 12-item Achievement Goal Questionnaire (AGQ) (Elliot \& McGregor, 2001) on a seven point Likert format anchored by 1: not at all true of me and 7: very true of me was used in this study. The scores on the questionnaire could range from 12 to 84 with middle point being 48 . While we are not aware of any previous validation of the AGQ for preservice teachers, the AGQ, originally targeted at university students, has been validated for elementary students (Senler \& Sungur, 2007) and sample items on the scale include mastery approach (e.g., I want to learn as much as possible from this class), performance approach (e.g., It is important for me to do well compared to others in this class), mastery avoidance (e.g., I am often concerned that I may not learn all that there is to learn in this class), and performance avoidance goals (e.g., I just want to avoid doing poorly in this class compared to others). Each of the subscales consists of three items.

Sungur and Senler (2010) reported reliabilities for the subscales to be adequate to conduct further analyses for the constructs: mastery approach goals $(\alpha=0.72)$, performance approach goals $(\alpha=0.69)$, mastery avoidance goals $(\alpha=0.66)$, and performance avoidance goals $(\alpha=0.63)$. Owens (2004) reported the following Cronbach alpha estimates for the AGQ: performance-approach, $\alpha=0.74$; performance-avoidance, $\alpha=0.75$; mastery-approach, $\alpha=0.88$; and mastery-avoidance, $\alpha=0.85$ while Van Yperen (2006) reported similar Cronbach alpha estimates for the AGQ: performance-approach, $\alpha=0.87$; performance-avoidance, $\alpha=0.62$; mastery-approach, $\alpha=0.80$; and mastery-avoidance, $\alpha=0.71$. Wang, Biddle and Elliot (2007) applied the $2 \times 2$ achievement goal framework in a physical education context in Singapore and the reported Cronbach alpha coefficients for the achievement goal scales were as follows: mastery-approach, $\alpha=.83$; performance-approach, $\alpha=.84$; mastery-avoidance, $\alpha$ $=.71$; performance-avoidance, $\alpha=.66$, respectively. 


\section{Design and Procedure}

Background information sheet was provided for the participants to indicate gender, age, and subject cohort. Prior to the administration of the research instrument, details of the study in face-to-face meetings with the participants were given and all participants were told that there was no wrong or right answer and that their responses would be anonymously treated. They were also assured that they could withdraw at any time from the study. Thereafter, one of the researchers with the support of two research assistants who were graduate students in the university administered the questionnaire to the preservice teachers in their respective cohorts during school hours, towards the end of the second semester of 2011/2012 academic session. The administration lasted 30 minutes on the average.

\section{Data Analysis}

In this study, two samples were drawn from two different cohorts (Education Science and Education Mathematics) in the same department of the same university and so we first investigated whether the samples could be pooled. To achieve this, a multivariate analysis of variance was conducted on subscale scores to examine whether group means were equivalent. Box's $M$ test and Levene's test were also computed to detect whether the variance-covariance matrix and variances were equivalent across groups. The multivariate results showed no difference between groups using Wilks' lambda criterion, $F(12,667)=.114, p=.87$. Box's test of equality of covariances also revealed no difference between groups $(p=.17)$, as did Levene's test for equality of variances (all $p>.05$ ). Based on these, the two samples were merged into one and all subsequent analyses are based on the combined sample even for the test-retest study. The responses of the participants to the 12 items of achievement goal orientations were subjected to principal components factor analyses (PCA) to identify their underlying dimensions.

Prior to this, the data screening process on the responses of the participants showed no missing values and no concern about normality, linearity, multicollinearity, and singularity. For example, subscale scores were normally distributed with skewness and kurtosis values within acceptable ranges (e.g. skewness ranged from -0.23 to -0.73 , kurtosis ranged from 0.26 to -0.97) as Kline (1998) suggested using absolute cut-off values of 3.0 for skewness and 8.0 for kurtosis. Also, inspection of the correlation matrix of the 12 items revealed that the correlations when taken overall were statistically significant as indicated by the Bartlett's test of sphericity, $\chi^{2}(66, \mathrm{~N}=680)=12208.89, p<.001$ which tests the null hypothesis that the corre- 
lation matrix is an identity matrix. The Kaiser- Meyer- Olkin measure of sampling adequacy (MSA) fell within acceptable range (values of .60 and above) with a value of .736. Each of the variables also exceeded the threshold value (.60) of MSA which ranged from .626 to .872 . Finally, most of the partial correlations were small as indicated by the anti-image correlation matrix. These measures all led to the conclusion that the set of 12 items of achievement goal orientations was appropriate for PCA and since no particular number of components was first hypothesized (although not unmindful of a priori criterion of four-factor) the criterion was set to eigenvalues greater than one (Kaiser, 1960; Tabachnick \& Fidell, 2001). The principal components analyses (PCA) were conducted on the responses of the participants to the 12 items of achievement goal orientations to determine their underlying dimensions.

\section{Results}

The initial unrotated PCA resulted in a factor model of four dimensions as indicated by the scree plot and eigenvalues exceeding unity. Thereafter, the a priori criterion of fourfactor was employed and this also lent support to a factor model of four dimensions. However, based on its pattern of factor loadings, this unrotated factor model was theoretically less meaningful and as such was difficult to interpret. Therefore, the analysis proceeded to rotate the factor matrix both orthogonally and obliquely to achieve a simple and theoretically more meaningful solution. One orthogonal rotation and one oblique rotation were run. Varimax rotation was used for the orthogonal solution, and oblimin rotation was used for the oblique solution.

Both rotations resulted in a factor model of four dimensions as suggested by the scree plot, a priori criterion of four-factor and eigenvalues exceeding unity. There were no remarkable differences between the orthogonal solution and the oblique solution in terms of factor structure and pattern of factor loadings. While we reported the factor loadings based on varimax rotation, we also reported the factor loadings based on oblimin rotation and as suggested by Tabachnick and Fidell (2001), the oblique solution was retained because the intercorrelations among the four achievement goals were positive: mastery approach goals were positively associated with mastery-avoidance, $r=.42(p<.001)$, performance-avoidance $r=.31$ $(p<.001)$ and performance-approach goals $r=.35(p<.001)$. Mastery-avoidance goals were positively related to performance-approach $r=.45(p<.001)$ and performance-avoidance goals $r=.43(p<.001)$ and the correlation between the two performance goals was also posi- 
tive $r=.53(p<.001)$ as indicated by the factor correlation matrix (Table 1). These findings are similar to those reported in a sport context (Conroy, Elliot, \& Hofer, 2003) with comparable correlations for 4 of the 6 permutations. More so, these findings of stronger associations between the two mastery goals and between performance-avoidance and mastery-approach are consistent with the results of Wang, Biddle, and Elliot (2007) in physical education context and this may be a manifestation of the context, age or culture. More research is needed to disentangle this issue when compared with that of Conroy, Elliot and Hofer (2003).

Table 1 below shows the descriptive statistics and intercorrelations among the achievement goal orientations in which the mean for mastery avoidance goals was close to the scale midpoint but this value was lower than the means for each of the other achievement goals orientations.

Table 1. Descriptive Statistics, Reliabilities, and Intercorrelations among Variables

\begin{tabular}{|c|c|c|c|c|c|c|c|}
\hline Variables & $\mathrm{M}$ & SD & Cronbach $\alpha$ & 1 & 2 & 3 & 4 \\
\hline 1 Mastery-approach goals & 4.03 & 1.04 & .90 & - & & & \\
\hline 2 Mastery-avoidance goals & 3.76 & 1.38 & .88 & $.42 *$ & - & & \\
\hline 3 Performance-approach goals & 3.90 & 1.19 & .93 & $.35^{*}$ & $.45^{*}$ & - & \\
\hline 4 Performance-avoidance goals & 3.88 & 1.13 & .86 & $.31 *$ & $.43^{*}$ & $.53^{*}$ & - \\
\hline
\end{tabular}

In this study, all the communalities for the factor analysis satisfied the minimum requirement of being larger than 0.50 , in fact these ranged from 0.797 to 0.982 . Figure 1 below is the scree plot which graphs the eigenvalue against the component number and is suggestive of a four component model.

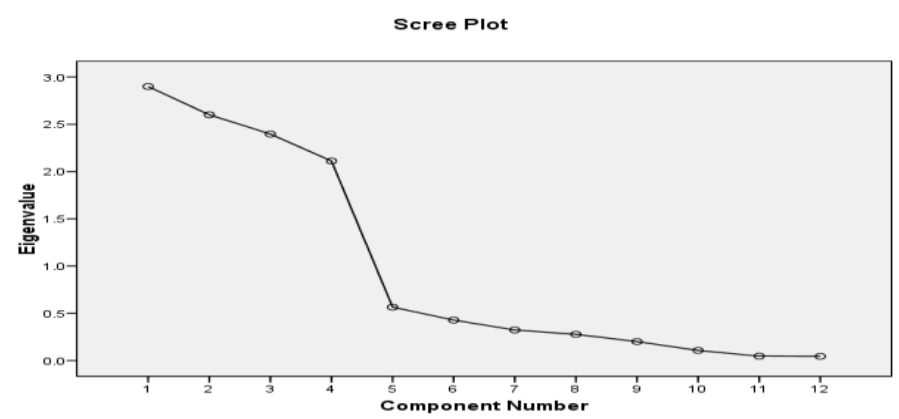

Figure 1. Cattell scree plot showing number of components and eigenvalues of the correlation matrix. 
Table 2 displays the factor loadings for the oblique and orthogonal (in parentheses) four-factor model of achievement goal orientations. All items loaded .75 and above on their primary factor; none of the secondary loadings exceeded .35. Together the four factors accounted for $84.07 \%$ of the total variance.

Table 2. Summary of Factor Loadings by Principal Components Analysis for the Oblique and Orthogonal (in parentheses) Four-Factor Model of Achievement Goal Orientations

Item

Factor loadings

$\begin{array}{llll}1 & 2 & 3 & 4\end{array}$

I want to learn as much as possible from this class

$.83(.81)$

$.93(.90)$

I desire to completely master the material presented in this class

It is important for me to understand the content of this course as

thoroughly as possible

$.84(.82)$

It is important for me to do better than other students

$.83(.81)$

$.90(.88)$

My goal in this class is to get a better grade than most of the other students

I worry that I may not learn all that I possibly could in this class

$.81(.80)$

$.84(.82)$

I am often concerned that I may not learn all there is to learn in this class

I just want to avoid doing poorly in this class

My fear of performing poorly in this class is often what motivates me

$.84(.82)$

My goal in this class is to avoid performing poorly

Note: $\quad$ Factor $1=$ mastery -approach goal orientation

Factor 2 = performance- approach goal orientation

Factor 3 = mastery - avoidance goal orientation

Factor 4 = performance -avoidance goal orientation

The first factor accounted for $24.22 \%$ of the variance (eigenvalue= 2.91 ) and consisted of three mastery-approach goal orientation items. The second factor accounted for $21.54 \%$ of the variance (eigenvalue $=2.59$ ) and consisted of three performance-approach goal orientation items. The third factor accounted for $20.65 \%$ of the variance (eigenvalue $=2.41$ ) and consisted of three mastery-avoidance goal orientation items. The fourth factor accounted for $17.66 \%$ of the variance (eigenvalue $=2.12$ ) and consisted of three performance-avoidance goal orientation items. 
According to Comrey and Lee (1992), factor loadings of .71 or higher can be regarded "excellent", .63 is "very good", .55 is "good", .45 is "fair", and .32 is "poor". Thus, variables with high loadings can be considered purer measures of the underlying factors. This means the loadings of .88 and above recorded in this study are vividly less trivial than say loadings of .30 or .40 although these are not recorded in the present study. While this study recognises the use of the percent of cumulative variance, Horn's parallel analysis (PA) (Horn, 1965), and Velicer's minimum average partial (MAP) test (Velicer, 1976 ) as fifth, sixth, and seventh (the order does not indicate the importance or accuracy attached) ways of making decisions regarding how many components or factors to include in a PCA or exploratory factor analysis (EFA), attempts were not made to explore them rather we settled for the Kaiser's stopping rule or $K 1$ method (Kaiser, 1960) which appears to be the best known and most utilized in practice (Fabrigar, Wegener, MacCallum, \& Strahan, 1999), the scree test (Cattell,1966), consider more accurate and less variable than the $K 1$ method (Zwick \& Velicer, 1986) and the number of non-trivial factors each of which yielded a factor model of four factors.

The internal consistency reliabilities for the subscales are: mastery-approach goals $(\alpha$ $=.90)$, performance-approach goals $(\alpha=.93)$, mastery-avoidance goals $(\alpha=.88)$, and performance-avoidance goals $(\alpha=.86)$ and the internal consistency reliability for the entire scale ( $\alpha=.82$ ) was considered very high and conceptually meaningful (Curtis \& Singh, 1997). Thus, the four measures represent empirically separable and internally consistent achievement goal constructs. Since the publication of AGQ in 2001, a good number of previous studies (Muis \& Winne, 2012; Sungur \& Senler, 2010; Muis, Winne, \& Edwards, 2009; Adesope, Carmen, \& Nisbit, 2008; Roebken, 2007; Senler \& Sungur, 2007; Van Yperen, 2006) have identified the questionnaire as consisting of four factors, namely: mastery-approach goals, performance-approach goals, mastery-avoidance goals, and performance-avoidance goals with reported very high reliability coefficients.

Generally in Nigeria, most researchers rather than taking pain to ascertain the psychometric properties of an adapted instrument whose development is foreign, they prefer to lean on the existing psychometric properties and cross-cultural methodologists have warned that the suitability, functionality, and appropriateness of an inventory developed in one society should not be taken for granted when adopted in another context (Hui \& Triandis, 1985). The four-factor solution recorded in this study is in agreement with those of previous studies as earlier indicted and this suggests that the AGQ could be considered to measure what it pur- 
ports to measure, even in this new context, thus confirming the invariance nature of the achievement goal orientation construct within the $2 \times 2$ framework (Muis \& Winne, 2012; Sungur \& Senler, 2010; Muis, Winne, \& Edwards, 2009; Adesope, Carmen, \& Nisbit, 2008; Roebken, 2007; Van Yperen, 2006).

\section{Discussion}

Pintrich (2000) explained that the stability of goal orientation across different contexts needs to be examined. Based on this, the present study provides theoretically-driven and empirically-based analyses that contribute to the body of research on psychometric properties of achievement goal orientation questionnaire in general and Elliot and McGregor $2 \times 2$ framework for AGQ in particular in an entirely different context and environment. Without restricting participants' responses, this study explored the possibility of a factor structure underlying the AGQ and a principal components factor analysis computed with oblimin and varimax rotations supported a four-factor model of achievement goal orientations namely, masteryapproach, performance-approach, mastery-avoidance, and performance-avoidance. This finding is in support of the generalisability of the $2 \times 2$ framework of goal orientation in a coursespecific context (Elliot \& McGregor, 2001) and also in tandem with a more domain-specific context of the $2 \times 2$ framework of goal orientation (Finney, Pieper, \& Baron, 2004). The trichotomous achievement goal introduced two forms of performance goals (Elliot, 1999; VandeWalle, 1997; Elliot \& Church, 1997; Middleton \& Midgley, 1997; Skaalvik, 1997): performance-avoidance and performance-approach both of which are concerned with demonstrating competence, but the former entails the desire to avoid appearing incompetent than others whereas the latter focuses on the desire to outperform others (Elliot \& Harackiewicz, 1996).

The $2 \times 2$ framework introduced the two forms of mastery goals (Elliot \& McGregor, 2001): mastery-approach and mastery-avoidance thereby fully crossed the masteryperformance goal distinction by approach-avoidance motivation to evaluate the following four types of goal orientations: performance-approach, performance-avoidance, mastery-approach, and mastery-avoidance goals. Elliot and McGregor (2001) tested this $2 \times 2$ achievement goal framework previously proposed by Pintrich (2000) and Elliot (1999) and determined the distinctiveness of mastery-approach and mastery-avoidance goal orientations, which had previously been defined as unidimensional mastery construct. In this new framework, a mastery 
approach orientation focuses on attaining positive possibilities such as acquiring new skills and improving one's competence, whereas a mastery avoidance orientation focuses on avoiding negative possibilities such as losing skills or becoming incompetent (Finney, Pieper, \& Baron, 2004). Although, recent research has proposed a $3 \times 2$ achievement goal model (Elliot, Muraya, \& Pekrun, 2011), determining the psychometric properties of the $2 \times 2$ AGQ is still a fruitful area of research and as determined in the present study a four-factor model of achievement goal with high alpha values for the subscales is established, a finding consistent with findings in previous studies that examined the psychometric properties of the $2 \times 2$ AGQ (Muis \& Winne, 2012; Muis, Winne, \& Edwards, 2009; Roebken, 2007; Elliot \& McGregor, 2001; Elliot \& Thrash, 2001).

Thus, this finding suggests that the questionnaire is not only suitable for use in Nigeria but that the instrument is culturally invariant at least with respect to the present study sample. One other vital aspect of this study was that the scores from each orientation had adequate internal consistency. The responses to the performance-avoidance items, however, had the lowest Cronbach's coefficient alpha (.86). Interestingly, achievement goal theorists and researchers (Sungur \& Senler, 2010; Van Yperen, 2006; Finney, Pieper, \& Baron, 2004; Elliot $\&$ McGregor, 2001) have found the same item to be the worst indicator for the performanceavoidance construct when used in both course-specific and domain-specific contexts and as suggested by Finney, Pieper, and Baron (2004), a test-retest reliability of the scores needs to be evaluated. In view of this suggestion, a three-week test-retest study was conducted on the whole sample and the reliability estimates of $.88, .90, .84$, and .81 for mastery-approach, performance-approach, mastery-avoidance, and performance-avoidance respectively were computed. The coefficient of test-retest reliability for the entire questionnaire was .79. As described in the literature, internal consistency reliability refers to the extent to which a set of items is homogeneous in its contribution to a scale or sub-test or full test score whereas testretest reliability refers to the stability or projected stability of the score over time (Merenda, undated). The test-retest reliability represents the proportion of the "true" score variance relative to the "observed" score variance that can be expected to be yielded by the measure.

Comparisons of the coefficients of test-retest reliability with coefficients of internal consistency reliability of the four constructs revealed that coefficients of test-retest reliability were lower than the coefficient of internal consistency reliability and this pattern is consistent with theoretical assertion in literature (Merenda, undated). Coefficients of test-retest reliabil- 
ity yielded in this study for each of the four constructs of $2 \times 2$ achievement goal orientation model showed that responses to the performance-avoidance items had the lowest test-retest reliability coefficient thus confirming our initial stand on this subscale and as earlier observed by others. In general, it is sounded widely that if an experimenter cannot attest to the possession of at least adequate psychometric properties of internal consistency reliability and evidences of a variety of validities for a measure then the experimenter is faced with the alternative of not using the measure or establishing them before proceeding to include it in a study as a variable (Anastasi, 1982; APA Standards, 1974, APA Joint Standards, 1985). The good internal consistency reliabilities and coefficients of test-retest reliability obtained here (and in other studies) suggest that the questionnaire would be found quite useful for educators in ascertaining the achievement goal orientation of their students most of whom are preservice teachers.

There are limitations relating to the present study. Future work revising or creating additional items to represent performance-avoidance may be deemed necessary if these items continue to perform poorly. More so, the predictive utility of the $2 \times 2$ course-specific measure of goal orientation with attention given to measures of effect size should be investigated with Nigerian sample as Elliot and McGregor (2001) found that when using the $2 \times 2$ framework in a course-specific context, performance-approach and performance-avoidance orientations were significant predictors of course-specific performance. In conclusion, the predictive utility of the $2 \times 2$ framework in a domain-specific measure of goal orientation with regard to achievement (Finney, Pieper, \& Baron, 2004) needs further study and the psychometric properties of the $2 \times 2$ Achievement Goals in Mathematics Education Questionnaire and Science Education Questionnaire should be tested and correlates of distinct achievement goal profiles examined in Nigerian cultures and elsewhere to generalise previous findings (Wang, Biddle, \& Elliot, 2007). 


\section{References}

Adesope, O. O., Carmen, L. Z. G., \& Nesbit, J. C. (2008). Validating the Psychometric Properties of Achievement Goal Questionnaire using Item Response Theory. Paper presented at the 2008 Annual Meeting of the Canadian Society for the Study of Education, May 31- June 3, Vancouver, B. C., Canada.

Adie, J. W., Duda, J. L., \& Ntoumanis, N. (2008). Achievement goals, appraisals, and the psychological and emotional welfare of sports participants. Journal of Sport and Exercise Psychology, 30, 302-322.

Akın, A. (2012). Achievement Goal Orientations and Age. TOJCE: The Online Journal of Counselling and Education, 1, 77-81.

Alao, S., \& Guthrie, J. T. (1999). Predicting conceptual understanding with cognitive and motivational variables. The Journal of Educational Research, 92, 243-254.

Aldhafri, S., Kazem, A., Alzubiadi, A., Yousif, Y., Al-Bahrani, M., \& Alkharusi, H. (2009). Developmental aspects for Omani adolescents (12-18 years): Piloting instruments and initial findings. ICET International Yearbook on Teacher Education-Maintaining strategic agility: Managing change and assuring quality in education for teaching (pp. 165-175). Wheeling, IL: National-Louis University.

Alkharusi, H. (2010). Validation of the Trichotomous Framework of Achievement Goals for Omani Students. Educational Research Journal, 25, 265-285.

American Psychological Association (1985). Joint Technical Standards for Educational and Psychological Testing, 4th Edition. Washington, D.C. APA.

American Psychological Association (1974). Standards for Educational and Psychological Tests, $3^{\text {rd }}$ Edition. Washington, D.C. APA.

Ames, C. (1992). Classrooms: Goals, structures, and student motivation. Journal of Educational Psychology, 84, 261-271. Doi:10.1037/0022-0663.84.3.261.

Ames, C., \& Archer, J. (1988). Achievement goals in the classroom: Students' learning strategies and motivation processes. Journal of Educational Psychology, 80, 260-267. Doi: 10.1037/0022-0663.79.4.409.

Ames, C., \& Archer, J. (1987). Mothers' beliefs about the role of ability and effort in school learning. Journal of Educational Psychology, 79, 409-414.

Anastasi, A. (1982). Psychological Testing. New York: MacMillan.

Archer. J. (1994). Achievement goals as a measure of motivation in university students. Contemporary Educational Psychology. 19, 430-446. Doi:10.1006/ceps.1994.1031. 
Awofala, A. O. A., \& Awolola, S. A. (2011). The effect of self-efficacy, anxiety, attitude, and previous mathematics achievement on senior secondary students' performance in mathematics. African Journal of Historical Sciences in Education, 7, 198 - 209.

Bandura, M., \& Dweck, C. (1985). The relationship of conceptions of intelligence and achievement goals to achievement-related cognition, affect and behaviour. Unpublished manuscript.

Barzegar, M. (2012). The Relationship between Goal Orientation and Academic Achievement- The Mediation Role of Self Regulated Learning Strategies- A Path Analysis. International Conference on Management, Humanity and Economics (ICMHE'2012) August 11-12, Phuket (Thailand), 112-115.

Beaubien, J. M., \& Payne, S. C. (1999, April). Individual goal orientation as a predictor of job and academic performance: A meta-analytic examination. Paper presented at the annual meeting of the Society for Industrial and Organizational Psychology, Atlanta, GA.

Bong, M. (2009). Age related differences in achievement goal differentiation. Journal of Educational Psychology, 101, 879-896. Doi: 10.1037/a0015945.

Brett, J. F., \& VandeWalle, D. (1999). Goal orientation and goal content as predictors of performance in a training program. Journal of Applied Psychology, 84, 863 - 873. Doi: 10.1037/0021-9010.84.6.863.

Brown, K. (2001). Using computers to deliver training: Which employees learn and why? Personnel Psychology, 54, 271-296. Doi: 10.1111/j.1744-6570.2001.tb00093.x.

Button, S. B., Mathieu, J. E., \& Zajac, D. M. (1996). Goal orientation in organizational research: A conceptual and empirical foundation. Organizational Behavior and Human Decision Processes, 67, 26-48. Doi: 10.1006/obhd.1996.0063.

Canpolat, A. M. (2012). The mediating role of Self-Efficacy in the relationship between class climates and goal orientations in Physical Education. World Applied Sciences Journal, $16,76-85$.

Cattell, R. B. (1966). The scree test for the number of factors. Multivariate Behavioral Research, 1, 245-276. Doi: 10.1207/si532706mbr0102_10.

Cellar, D. F., Stuhlmacher, A. F., Young, S. K., Fisher, D. M., Adair, C. K., Haynes, S., \& Twichell, E. (2011). Trait goal orientation, self-regulation, and performance: A metaanalysis. Journal of Business Psychology, 26, 467-483. Doi: 10.1007/s10869.010.9201.6. 
Chan, K. W., \& Lai, P. Y. (2007). Revisiting the trichotomous achievement goal framework for Hong Kong secondary students: A structural model analysis. The Asia-Pacific Education Researcher, 16, 11-22.

Chen, G., Gully, S. M., Whiteman, J., \& Kilcullen, R. N. (2000). Examination of relationships among trait-like individual differences, state- like individual differences, and learning performance. Journal of Applied Psychology, 85, 835-847. Doi: 10.1037/00219010.85.6.835.

Colquitt, J. A., \& Simmering, M. J. (1998). Conscientiousness, goal orientation, and motivation to learn during the learning process: A longitudinal study. Journal of Applied Psychology, 83, 654-665. Doi:apa.org/psycinfo/1998-10357-012.

Comrey, A. L., \& Lee, H. B. (1992). A first course in factor analysis (2nd ed.). Hillsdale, NJ: Erlbaum.

Conroy, D. E., Elliot, A. J. \& Hofer, S. M. (2003). A $2 \times 2$ achievement goals questionnaire for sport. Journal of Sport and Exercise Psychology, 25, 456-476. Doi: 10.1037/00223514.80.3.501.

Coutinho, S. A., \& Neuman, G. (2008). A model of metacognition, achievement goal orientation, learning style and self-efficacy. Learning Environment Research, 11, 131-151. Doi: 10.1007/s10984-008-9042-7.

Curtis, W. J., \& Singh, N. N. (1997). The psychometric characteristics of the Henderson environmental learning process scale. Educational and Psychological Measurement, 57, 280-291. Doi: 10.1177/0013164497057002007.

DeGeest, D., \& Brown, K. G. (2011). The role of goal orientation in leadership development. Human Resource Development Quarterly, 22, 157-175. Doi: 10.1002/hrdq.20072.

DeShon, R. P., \& Gillespie, J. Z. (2005). A motivated action theory account of goal orientation. Journal of Applied Psychology, 90, 1096-1127. Doi: 10.1037/00219010.90.6.1096.

Dinc, Z. F. (2010). Relationship between achievement goal orientation and physical selfperception among students attending Physical Education teaching. World Applied Sciences Journal, 11, 662-668.

Diseth, A. (2011). Self-efficacy, goal orientations and learning strategies as mediators between preceding and subsequent academic achievement. Learning and Individual Differences, 21, 191-195. Doi:10-1016/j.lindif.2011.01.003.

Dweck C. S. (1986). Motivational processes affecting learning. American Psychologist, 41, 148-156. Doi: 10.1037/0003-066X.41.10.1040. 
Dweck, C. S., \& Leggett, E. L. (1988). A social cognitive approach to motivation and personality. Psychological Review, 95, 256-273. Doi: 10.1371/journal.pone.0036680.

Elliot, A. J. (1999). Approach and avoidance motivation and achievement goals. Educational Psychologist, 34, 169-189. Doi: 10.1207/s15326985ep3403_3.

Elliot, A. J., \& Church, M. (1997). A hierarachical model of approach and avoidance achievement motivation. Journal of Personality and Social Psychology, 72, 218-232. Doi: 10.1037/0022-3514.72.1.218.

Elliot, A. J., \& Harackiewicz, M. (1996). Approach and avoidance achievement goals and intrinsic motivation: A mediational analysis. Journal of Personality and Social Psychology, 70, 461-475.

Elliot, A. J., \& McGregor, H. A. (2001). A $2 \times 2$ Achievement Goal Framework. Journal of Personality and Social Psychology, 80, 501-519. Doi: 10.10371/0022-3514.80.3.501.

Elliot, A. J., \& Murayama, K. (2008). On the measurement of achievement goals: critique, illustration, and application. Journal of Educational Psychology, 100, 613-628. Doi: 10.1037/0022-0663.100.3.613.

Elliot, A. J., Murayama, K., \& Pekrun, R. (2011). A 3×2 Achievement Goal Model. Journal of Educational Psychology, 103, 632-648. Doi: 10.1037/a0023952.

Elliot, A. J., \& Reis, H. T. (2003). Attachment and exploration in adulthood. Journal of Personality and Social Psychology, 85, 317-331. Doi:10.1037/0022-3514.85.2.317

Elliot, A. J., \& Thrash, T. M. (2001). Achievement goals and the hierarchical model of achievement motivation. Educational Psychology Review, 12, 139-156. Doi: 10.1023/A:1009057102306.

Fabrigar, L. R., Wegener, D. T., MacCallum, R. C., \& Strahan, E. J. (1999). Evaluating the use of exploratory factor analysis in psychological research. Psychological Methods, 3, 272-299. Doi: apa.org/psycinfo/1999-03908-004.

Finney, S. J., Pieper, S. L., \& Barron, K. E. (2004). Examining the psychometric properties of the achievement goal questionnaire in a general academic context. Educational and Psychological Measurement, 64, 365-382. Doi: 10.1177/0013164403258465.

Fisher, S. L., \& Ford, J. K. (1998). Differential effects of learner effort and goal orientation on two learning outcomes. Personnel Psychology, 51, 397-420. Doi: 10.1111/j.17446570.1998.tb00731.x.

Fiske, A. P. (2002). Using individualism and collectivism to compare cultures: A critique of the validity and measurements of the constructs: Comment on Oyserman et al. (2002). Psychological Bulletin, 128, 78-88. Doi: apa.org/journals/bul/128/1/78. 
Ford, J. K., Smith, E. M., Weissbein, D. A., Gully, S. M., \& Salas, E. (1998). Relationships of goal orientation, metacognitive activity, and practice stnitegies with learning outcomes and transfer. Journal of Applied Psychology, 83, 218-23. Doi:10.1037/00219010.83.2.218.

Fryer, J. W., \& Elliott, A. J. (2007). Stability and change in achievement goals. Journal of Educational Psychology, 99, 700-714. Doi: 10.1037/0022-0663.99.4.700.

Harackiewicz, J. M., Barron, K. E., Elliot, A. J., Carter, S. M., \& Lehto, A. T. (1997). Predictors and consequences of achievement goals in the college classroom: Maintaining interest and making the grade. Journal of Personality and Social Psychology, 73, 12841295. Doi:10.1037/0022-3514.73.

Harackiewicz, J., Barron, K. E., Tauer, J. M., Carter, S. M., \& Elliot, A. J. (2000). Short-term and long-term consequences of achievement goals: Predicting interest and performance over time. Journal of Educational Psychology, 92, 316-330. Doi:apa.org/psycinfo/2000-07799-008.

Harackiewicz, J. M., \& Elliot, A. J. (1998). The joint effects of target and purpose goals on intrinsic motivation: A mediational analysis. Personality and Social Psychology Bulletin, 24, 675-68.

Heyman, G. D., \& Dweck C. (1992). Achievement goals and intrinsic motivation: Their relation and their role in adaptive motivation. Motivation and Emotion, 16, 231-247. Doi: 10.1007/BF00991653.

Horn, J. L. (1965). A rationale and test for the number of factors in factor analysis. Psychometrika, 30, 179-185. Doi: 10.1007/s11121-011-0201-1.

Hui, C. H., \& Triandis, H. C. (1985). Measurement in cross-cultural psychology: A review and comparison of strategies. Journal of Cross-Cultural Psychology, 16, 131-152. Doi: $10.1177 / 0022002185016002001$.

Jagacinski, C. M., \& Duda, J. L. (2001). A comparative analysis of contemporary achievement goal measures. Educational and Psychological Measurement, 61, 1013-1039. Doi: 10.1177/00131640121971626.

Järvelä, S. (1996). Cognitive apprenticeship model in a complex technology-based learning environment: Socio-emotional processes in learning interaction. Publications in Education, No 30. University of Joensuu.

Kaiser, H. F. (1960). The application of electronic computers to factor analysis. Educational and Psychological Measurement, 20, 141-151. Doi:10.1177/001316446002000116. 
Kim, Y. S, (2008). Effects of achievement goal orientation of dental school students on selfmotivation self-regulated learning strategies and self-efficacy. Korean Journal of Medical Education, 20, 199-208. http://dx.doi.org/10.3946/kjme.2008.20.3.199.

Kline, R. (1998). Principles and practice of structural equation modeling. New York: Guilford Press.

Kozlowski, S. J., Gully, S. M., Brown, K. G., Salas, E., Smith, E. M., \& Nason, E. R. (2001). Effects of training goals and goal orientation traits on multidimensional training outcomes and performance adaptability. Organizational Behavior and Human Decision Processes, 85, 1-31.

Mangos, P., \& Steele-Johnson, D. (2001). The role of subjective task complexity in goal orientation, self-efficacy, and performance relations. Human Performance, 14, 169 186. Doi:10.1207/S15327043HUP1402_03.

McKinney, A. P. (2003). Goal Orientation: A Test of Competing Models. Unpublished Ph.D Dissertation. Virginia Polytechnic Institute and State University, Blacksburg, Virginia. Meece, J. L., Blumenfeld, P., \& Hoyle, R. (1988). Students' goal orientations and cognitive engagement in classroom activities. Journal of Educational Psychology, 80, 514-523.

Merenda, F. (n.d). Errors in Analysis and Writing. Available at http://www.amsci.com/authors/author-resources/

Middleton, M., \& Midgley, C. (1997). Avoiding the demonstration of lack of ability: An underexplored aspect of goal theory. Journal of Educational Psychology, 89, 710-718. Doi:apa.org/psycinfo/1997-43826-012.

Midgley, C., Kaplan, A., \& Middleton, M. (2001). Performance-approach goals: Good for what, for whom, under what circumstances, and at what cost? Journal of Educational Psychology, 93, 77-86. Doi:apa.org/psycinfo/2001-16705-008.

Midgley, C., Kaplan, A., Middleton, M., Maehr, M. L., Urdan, T., Anderman, L. H., Anderman, E., \& Roeser, R. (1998). The development and validation of scales assessing students' achievement goal orientations. Contemporary Educational Psychology, 23, 113-131.

Muís, K. R., \& Winne, P. H. (2012). Assessing the psychometrics properties of achievement goals orientation questionnaire across task contexts. Canadian Journal of Education, 35, 232-248.

Muís, K. R., Winne, P. H. \& Edwards, O. V. (2009). Modern psychometrics for assessing achievement goal orientation: A Rasch analysis. British Journal of Educational Psychology, 79, 547-576. Doi: 10.1348/000709908X383472. 
Nicholls, J. G. (1975). Causal attributions and other achievement-related cognitions: Effects of task outcome, attainment value, and sex. Journal of Personality and Social Psychology, 31, 379-389. Doi:apa.org/psycinfo/1975-21149-001.

Nicholls, J. G., Cobb, P., Wood, T., Yackel, E., \& Patashnick, M. (1990). Assessing students' theories of success in mathematics: Individual and classroom differences. Journal for Research in Mathematics Education, 21, 109-122. Doi: 10.2307/749138.

Nicholls, J. G., Patashnick, M., \& Nolen, S. B. (1985). Adolescents' theories of education. Journal of Educational Psychology, 77, 683-692.

Nien, C. L., \& Duda, J. L. (2008). Antecedents and consequences of approach and avoidance achievement goals: A test of gender invariance. Psychology of Sport and Exercise, 9, 352-372. Doi:10.1016/ j.psychsport.2007.05.002.

Njouku, H. U. (2007). The interrelations of goals, knowledge monitoring, strategic help seeking, and achievement among high school students of different cultures. Dissertation Abstracts International Section A: Humanities and Social Sciences, 68(4-A), 1328.

Owens, K. M. (2004, April). The relationship between achievement goal orientation and item difficulty selection in a self-adapted test. Poster session presented at the annual meeting of the National Council of Measurement in Education, San Diego, CA.

Payne, S. C., Youngcourt, S. S., \& Beaubien, J. M. (2007). A meta-analytic examination of the goal orientation nomological net. Journal of Applied Psychology, 92, 128-150. Doi:10.1037/0021-9010.92.1.128.

Phillips, J. M., \& Gully, S. M. (1997). Role of goal orientation, ability, need for achievement, and locus of control in the self-efficacy and goal-setting process. Journal of Applied Psychology, 82, 792-802. Doi:apa.org/journals/apl/82/5/792.

Pintrich, P. R. (2000a). An achievement goal theory perspective on issues in motivation terminology, theory and research. Contemporary Educational Psychology, 25, 92-104. Doi: 10.1006/ceps.

Pintrich, P. R. (2000b). Multiple goals, multiple pathways: The role of goal orientation in learning and achievement. Journal of Educational Psychology, 92, 544- 555. Doi:apa.org/psycinfo/2000-12129-013.

Pintrich, P. R., \& Schunk, D. H. (2002). Motivation in education: Theory, research and applications. Upper Saddle River, NJ: Merrill Prentice Hall.

Roebken, H. (2007). Multiple goals, satisfaction, and achievement in university undergraduate education: A Student Experience in the Research University (SERU) project re- 
search paper. California: University of Clifornia, Berkeley, Centre for Studies in Higher Education.

Roussel, P., Elliot, A. J. \& Feltman, R. (2011). The influence of achievement goals and social goals on help-seeking from peers in an academic context. Learning and Instruction, 21, 394 - 402. Doi:10.1016/j.learninstruc.2010.05.003.

Senko, C., \& Harackiewicz, J. M. (2005). Regulation of achievement goals: The role of competence feedback. Journal of Educational Psychology, 97, 320-336. Doi: 10.1037/0022-0663.97.3.320.

Senler, B., \& Sungur, S. (2007, November) Hedef yonelimi anketinin Türkc, e’ye cevrilmesi ve adaptasyonu [Translation and adaptation of achievement goals questionnaire to Turkish]. Paper presented at 1. Ulusal Ilkogretim Kongresi, Ankara, Turkey.

Seo, D. (2000). The Motivational Construct in Mathematics Learning Using Structural Equation Modeling: The Korean Elementary School Math Class. $<$ http://eric.ed.gov/ERICDocs/data/ericdocs2sq1/content_storage_01/00000(19b/80/16/ b5 /2d.pdf> (Downloaded 25.5.2009).

Sideridis, G. D. (2008). The regulation of affect, anxiety and stressful arousal from adopting mastery avoidance goal orientations. Stress and Health, 24, 55-69. Doi: 10.1002/smi.1160.

Skaalvik, E. (1997). Self-enhancing and self-defeating ego orientations: Relations with task and avoidance orientation, achievement, self-perceptions, and anxiety. Journal of Educational Psychology, 89, 71-81. Doi: apa.org/journals/edu/89/1/71.

Smith, R. E., Smoll, F. L. \& Cumming, S. P. (2009). Motivational climate and changes in young athletes' achievement goal orientations. Motivation Emotion, 3, 173-183.

Somuncuoglu, Y., \& Yildirim, A. (1999). The relationship between achievement goal orientations and the use of learning strategies. The Journal of Educational Research, 92, $267-$ 277.

Steele-Johnson, D., Beauregard, R. S., Hoover, P. B., \& Schmidt, A. M. (2000). Goal orientation and task demand effects on motivation, affect, and performance. Journal of Applied Psychology, 85, 724-738.

Stevenson, S. J. (2011). Elliot's (1999) 2 X 2 Model of Achievement Motivation: A Metaanalysis of the empirical literature in Physical Activity and Education. A Ph.D Dissertation, Texas Tech University. 
Sungur, S., \& Senler, B. (2010). Students' achievement goals in relation to academic motivation, competence expectancy, and classroom environment perceptions. Educational Research and Evaluation, 16, 303-324. Doi: 10.1080/13803611.2010.523291.

Tabachnick, B. G., \& Fidell, L. S. (2001). Using multivariate statistics. 4th edition. Boston, MA, Allyn \& Bacon.

Tao, V., \& Hong, Y. Y. (2000). A meaning system approach to Chinese students' achievement goals. Journal of Psychology in Chinese Societies, 1, 13-38.

Urdan, T. (2004). Predictors of academic self-handicapping and achievement: Examining achievement goals, classroom goal structures, and culture. Journal of Educational Psychology, 96, 251-264. Doi:apa.org/journals/edu/96/2/251.

Valle, A., Cabanach, R. G., Núñez, J. G., González-Pienda, J., Rodríguez, S. \& Piñero. I. (2003). Multiple goals, motivation and academic learning. British Journal of Educational Psychology, 73, 71-87.

VandeWalle, D. (1997), Development and validation of a work domain goal orientation instrument, Educational and Psychological Measurement, 8, 995-1015.

VandeWalle, D., Brown, S. P., Cron, W. L. \& Slocum, J. W, Jr (1999). The influence of goal orientation and self-regulation tactics on sales performance: A longitudinal field test. Journal of Applied Psychology, 84, 249-259. Doi: apa.org/psycinfo/1999-13895-008.

VandeWalle, D., Cron, W. L., Slocum, J. W., (2001). The role of goal orientation following performance feedback. Journal of Applied Psychology, 86, 629-40. Doi: 10.1037/0021-9010.86.4.629.

VandeWalle, D., \& Cummings, L L. (1997). A test of the influence of goal orientation on the feedback-seeking process. Journal of Applied Psychology, 82, 390-400. Doi: apa.org/psycinfo/1997-06155-005.

Van Yperen, N. W. (2006). A novel approach to assessing achievement goals in the context of the $2 \times 2$ framework: Identifying distinct profiles of individuals with different dominant achievement goals. Personality and Social Psychology Bulletin, 32, 1432-1445. Doi: $10.1177 / 0146167206292093$.

Velicer, W. F. (1976). Determining the number of components from the matrix of partial correlations. Psychometrika, 41, 321-327.

Wang, J. C. K., Biddle, S. J. H., \& Elliot, A. J. (2007). The 2 x 2 achievement goal framework in a physical education context. Psychology of Sport and Exercise, 8, 147-168. Doi:10.1016/j.psychsport.2005.08.012. 
Was, C. (2006). Academic Achievement Goals Orientation: Taking Another Look. Electronic Journal of Research in Educational Psychology, 4, 529-550.

Winne, P. H., Muis, K. R., \& Jamieson-Noel, D. J. (2005). Relationships among achievement goal orientation, calibration bias and performance in response to successive feedback in an undergraduate course. Paper presented at the annual American Educational Research Association.

Zwick, W.R., \& Velicer, W.F. (1986). Comparison of five rules for determining the number of components to retain. Psychological Bulletin, 99, 432-442. Doi:apa.org/psycinfo/1986-21041-001. 